\title{
PREPARAÇÃO, CARACTERIZAÇÃO E PROPRIEDADES DE FILMES POLIMÉRICOS COM POTENCIAL APLICAÇÃO NO RECOBRIMENTO DE SEMENTES
}

\author{
Aline F. de Oliveira e Valdir Soldi* \\ Departamento de Química, Universidade Federal de Santa Catarina, 88040-900 Florianópolis - SC, Brasil \\ Cileide Maria Medeiros Coelho, Aquidauana Miqueloto e Jefferson L. M. Coimbra \\ Departamento de Fitotecnia, Universidade do Estado de Santa Catarina, 88520-000 Lages - SC, Brasil
}

Recebido em 10/11/08; aceito em 27/3/09; publicado na web em 10/8/09

\begin{abstract}
PREPARATION, CHARACTERIZATION AND PROPERTIES OF POLYMERIC FILMS WITH POTENTIAL APPLICATION IN SEED COATINGS. Films of sodium carboxymethyl cellulose, sodium alginate and their mixture were evaluated in terms of interactions between the polymers, morphology, water absorption and application as seed coatings. FTIR analysis suggested that only hydrophobic interactions occurred between the polymers. The coating of bean seeds was confirmed by microscopy, indicating the formation of dense and homogeneous films with $7 \mu \mathrm{m}$ thickness. The obtained films did not affect the germination capacity of the seeds. In summary, the characteristics and properties of the films formed and the water absorption capacity, indicate that these systems are viable for use in seed coating processes.
\end{abstract}

Keywords: polysaccharide films; seed coatings; germination.

\section{INTRODUÇÃO}

O recobrimento de sementes, ou peliculização, consiste na deposição de uma camada fina e uniforme de um polímero na superfície da semente. O material polimérico pode ser utilizado conjuntamente com o tratamento químico e biológico em quantidade suficiente para recobrir a semente, produzindo, em consequência, um impacto mínimo sobre o meio ambiente. Este procedimento tem sido utilizado com o objetivo de preservar as sementes da ação de fungos (patógenos) presentes tanto na semente como no solo, garantindo desta forma, a germinação e o desenvolvimento das plântulas no campo. ${ }^{1,2}$

$\mathrm{O}$ interesse no desenvolvimento de filmes ou coberturas a partir de polímeros biodegradáveis está associado tanto à possibilidade de redução do uso de materiais sintéticos que degradam lentamente no meio ambiente, como a oportunidade para utilizar matérias-primas renováveis, principalmente as derivadas de produtos agrícolas, na produção de filmes. . $^{3,4}$

A utilização da técnica de recobrimento de sementes com uma camada polimérica fina e uniforme tem sido importante para incorporação, por exemplo, de nutrientes, fungicidas e outros aditivos. ${ }^{5-9}$ Filmes poliméricos podem ainda atuar como uma barreira a elementos externos tais como umidade, óleo e gases, conferindo maior proteção ao produto recoberto. Por outro lado, uma característica importante e necessária nos filmes de recobrimento, é que estes não afetem negativamente o processo de germinação e vigor das sementes. Por exemplo, estudos recentes envolvendo o processo de germinação de sementes de brócolos recobertas por filmes formados por hidroxietilcelulose,${ }^{10}$ quitosana e gelatina, ${ }^{11}$ pectina/ácido esteárico e pectina/gelatina, ${ }^{12}$ mostraram que o processo de germinação e vigor das plântulas não foi diferente em sementes com e sem recobrimento. Ainda, o recobrimento de sementes de salsa com filmes de quitosana e gelatina não afetou a qualidade das sementes em termos da capacidade de germinação. ${ }^{11}$ Pires e colaboradores ${ }^{9}$ avaliaram o efeito do tempo de armazenamento na germinação de sementes de feijão recobertas com poli vinil acetato (PVA) associado a fungicidas. Os autores constataram que a porcentagem de germinação não foi afetada em um período de até quatro meses de armazenamento.

*e-mail: vsoldi@qmc.ufsc.br
Em outro estudo, Pereira e colaboradores ${ }^{8}$ avaliaram a qualidade e a capacidade de germinação de sementes de milho em termos do recobrimento por filmes poliméricos e tempo de armazenamento. Os autores concluíram que o recobrimento não afetou a germinação das sementes por um período de até seis meses de armazenamento.

Os polissacarídeos, carboximetilcelulose (CMC) e alginato de sódio (AS) utilizados no presente estudo apresentam boa capacidade de formação de filmes, géis e hidrogéis. ${ }^{13-18}$ A CMC é um polímero natural, éter de celulose, que possui como estrutura base o polímero $\beta(1 \rightarrow 4)$-D-glucopiranose da celulose. Por outro lado, AS é um polissacarídeo de origem natural derivado principalmente de algas marinhas marrons, formado por cadeias lineares de $\beta(1 \rightarrow 4)$-D-ácido manurônico e $\alpha(1 \rightarrow 4)$-L-ácido gulurônico. Entre as principais aplicações, destacam-se a ampla utilização de ambos em processos de liberação de princípios ativos na área farmacêutica, ${ }^{19,20}$ como filmes comestíveis protetores na indústria alimentícia ${ }^{4,21}$ e como agente de liberação de pesticidas e nutrientes na área agrícola. ${ }^{22-25}$

O objetivo do presente estudo foi avaliar as propriedades de filmes de CMC e AS e da mistura CMC/AS (50/50) utilizados no recobrimento de sementes, neste caso específico, sementes de feijão (Phaseolus Vulgaris L.) e o efeito dos mesmos no processo de germinação e vigor das plântulas. Aspectos inerentes à interação entre os componentes da mistura CMC/AS, morfologia e propriedades de absorção e permeação a vapores de água dos filmes poliméricos foram tipicamente avaliados. Considerando a similaridade estrutural dos dois polissacarídeos, a utilização da mistura CMC/AS (50/50) apresenta-se como uma boa alternativa para diminuição de custos (o AS é ainda considerado como uma matéria-prima de custo elevado quando comparado à (MC), sem ocorrer perda na capacidade de formar filmes finos e homogêneos comparativamente aos polissacarídeos puros.

\section{PARTE EXPERIMENTAL}

\section{Preparação dos filmes e recobrimento das sementes}

O processo de recobrimento de sementes foi realizado a partir das soluções formadoras dos filmes nas proporções CMC/AS: 100/0, $50 / 50$ e 0/100, com uma concentração total de $2 \%$ (m/v). Após agi- 
tação da solução filmogênica por $24 \mathrm{~h}$, as sementes foram recobertas utilizando-se em média $1 \mathrm{~mL}$ de solução polimérica para cada 100 sementes. Após o recobrimento as sementes foram secas em estufa com circulação de ar na temperatura de $35^{\circ} \mathrm{C}$.

Nas análises e testes específicos de germinação foram utilizadas sementes não recobertas (controle) e sementes recobertas com filmes nas composições CMC/AS: 100/0, 50/50 e 0/100. Nos filmes CMC/ AS 50/50, foram avaliadas ainda diferentes concentrações da solução filmogênica $(1,2$ e $3 \% \mathrm{~m} / \mathrm{v})$ e diferentes ciclos de recobrimento (sementes recobertas 1,2 e 3 vezes).

\section{Espectroscopia de infravermelho}

Com objetivo avaliar possíveis interações entre os dois polímeros foram realizadas análises de FTIR nos filmes de composição CMC/ AS: 100/0, 50/50 e 0/100 na concentração total de 0,2\% (m/v), num equipamento Perkim Elmer, modelo 16 PC.

\section{Microscopia eletrônica de varredura}

A morfologia das sementes com e sem recobrimento foi avaliada através de microscopia eletrônica de varredura (Microscópio modelo Philips XL 30 equipado com microssonda de energia dispersiva (EDAX)). Para comprovar o recobrimento foram realizadas análises de microssonda de energia dispersiva para mapeamento do elemento $\mathrm{Na}^{+}$presente na estrutura de ambos os polímeros. Ainda com o intuito de avaliar o recobrimento (formação de filme) foi analisada a secção transversal da semente com e sem recobrimento. Neste experimento foi utilizado somente o filme CMC/AS 50/50 com três ciclos de recobrimento.

\section{Absorção e permeação a vapores de água}

Para o estudo de absorção de água, amostras nas dimensões 3 x 3 $\mathrm{cm}$ foram secas em estufa a vácuo por $24 \mathrm{~h}$, pesadas e acondicionadas em dessecadores contendo diferentes soluções salinas (saturadas) correspondentes às umidades relativas de $75 \%$ (cloreto de sódio) e 98\% (sulfato de sódio anidro). Em determinados intervalos de tempo a massa de água absorvida pelo filme foi determinada até alcançar o equilíbrio de massa. O conteúdo de água absorvido (\%WU) foi calculado de acordo com a Equação 1, onde $M_{0}$ é a massa da amostra seca no tempo zero e $\mathrm{M}_{\mathrm{a}}$ a massa da amostra nos diferentes intervalos de tempo. As análises foram realizadas em triplicata.

$\% W U=\frac{M_{\mathrm{a}}-M_{O}}{M_{O}} \times 100$

A permeabilidade ao vapor de água (WVP) foi determinada em umidades relativas de 43,75 e $98 \%$ através do método gravimétrico baseado na metodologia ASTM E-96-00. ${ }^{26} \mathrm{O}$ ganho de massa foi quantificado numa balança analítica com resolução de $0,1 \mathrm{mg}$. Os valores de permeabilidade foram calculados de acordo com a Equação 2, onde $w$ é quantidade de umidade adsorvida, $x$ a espessura do filme, $A$ a área do filme exposta aos vapores de água $\left(\mathrm{m}^{2}\right), p_{2}-p_{1}$ a diferença de pressão de vapor (Pa) e $t$ o tempo (s). As determinações foram realizadas em triplicata.

$W V P=\frac{w \cdot x}{A t\left(p_{2}-p_{1}\right)}$

\section{Teste de germinação e vigor}

O teste de germinação foi realizado segundo normas para Análises de Sementes (RAS; Brasil, 1992) ${ }^{27}$ Amostras com 200 sementes por tratamento (controle, CMCAS 100/0, 50/50 e 0/100) foram divididas em quatro grupos de 50 sementes (controle e amostra em triplicata) para os testes de germinação em dois ambientes: condições de laboratório $\left(25^{\circ} \mathrm{C}\right.$ e UR $\left.\cong 99 \%\right)$ e casa de vegetação (areia) $\left(22{ }^{\circ} \mathrm{C}\right.$ e UR $\cong 70 \%$ ). Na condição de laboratório, as sementes foram colocadas em papel de germinação Germitex ${ }^{\circledR}$, umedecidas com água destilada (até 2,5 vezes o peso do papel) e mantidas na câmara controlada por um período de 5 dias, para posterior contagem das sementes que germinaram e medições do comprimento da radícula e hipocótilo (parâmetros relacionados ao vigor da plântula).

Nas condições de casa de vegetação, as sementes foram colocadas em bandejas com areia previamente lavada e esterilizada em uma profundidade aproximada de $3 \mathrm{~cm}$. Após um período de 5 dias, realizou-se a contagem de plântulas germinadas e as medidas do comprimento da radícula e do hipocótilo.

Estudos de germinação das sementes em diferentes concentrações e diferentes ciclos para o filme CMC/AS 50/50, foram realizados somente em condições de laboratório.

\section{RESULTADOS E DISCUSSÃO}

\section{Espectroscopia de infravermelho}

Os espectros de FTIR mostrados na Figura 1 (região de 1800-500 $\mathrm{cm}^{-1}$ ) para os componentes puros e mistura CMC/AS 50/50 confirmam a similaridade das estruturas químicas dos dois biopolímeros. Nesta região, bandas de absorção características da CMC são observadas em $1596 \mathrm{~cm}^{-1}$ (estiramento $\mathrm{C}=\mathrm{O}$ de grupos carboxílicos), $1418 \mathrm{~cm}^{-1}\left(\mathrm{CH}_{2}\right.$ de grupos carboxílicos), $1324 \mathrm{~cm}^{-1}$ (absorção do grupo $\mathrm{CH}_{2}$ ) e $1063 \mathrm{~cm}^{-1}$ (estiramento C-O). Para o AS as mesmas absorções são observadas em $1608,1415,1300$ e $1036 \mathrm{~cm}^{-1}$. Por outro lado, as bandas referentes a estas absorções na mistura CMC/AS 50/50 foram intermediárias aos dois polissacarídeos puros e, de certa forma, mais próximas das absorções do alginato puro. Especificamente com relação à mistura CMC/AS 50/50, não foram observadas bandas características de ligações éster na região de 1700 e $1200 \mathrm{~cm}^{-1}$, sugerindo a ausência de interações químicas fortes entre os dois polímeros. Aparentemente, as interações entre os dois componentes são do tipo hidrofóbico, como observado por Alvarez-Lorenso e colaboradores ${ }^{28}$ para o sistema CMC/hidroxipropilmetilcelulose e Zhang ${ }^{29}$ para a mistura CMC/hidroxietilcelulose.

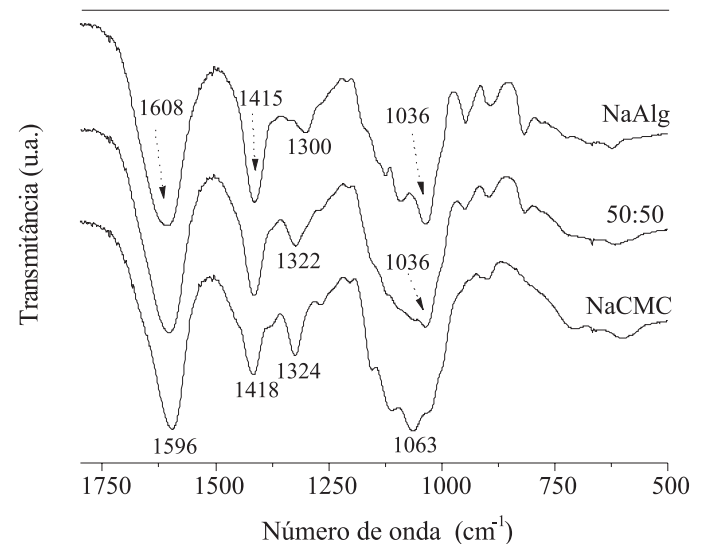

Figura 1. Espectros de infravermelho dos filmes $(0,1 \% \mathrm{~m} / \mathrm{v})$ de carboximetilcelulose e alginato de sódio e da mistura CMC/AS 50/50

\section{Microscopia eletrônica de varredura}

A eficiência no processo de recobrimento foi avaliada através de microscopia eletrônica de varredura considerando tanto a superfície, 
como a secção transversal das sementes. Embora visualmente fosse observado um aumento no brilho da superfície recoberta, a análise via microscopia eletrônica de varredura mostrou uma grande similaridade das superfícies recobertas com aquela não recoberta (Figura 1S, Material Suplementar). Aparentemente, com a presença de CMC os filmes formados na superfície das sementes foram mais transparentes. No entanto, uma significativa modificação na superfície é observada quando o alginato de sódio puro foi utilizado. Neste caso, a superfície apresenta-se mais homogênea e aparentemente com uma característica mais opaca. As diferenças observadas entre os filmes de CMC e AS devem estar associadas a diferenças na cristalinidade dos biopolímeros. Por outro lado, as micrografias parecem refletir essencialmente o relevo e a morfologia da superfície externa das sementes analisadas. Com o objetivo de confirmar a formação dos filmes, foram simultaneamente obtidos espectros de microssonda de energia dispersiva (EDS) com o intuito de monitorar a presença do íon sódio presente em ambos os polímeros utilizados (espectros não mostrados). $\mathrm{O}$ aumento da intensidade do pico correspondente ao íon sódio nas supefícies recobertas, comparativamente à não recoberta, confirmou a presença dos biopolímeros (filme polimérico) na superfície das sementes.

Uma análise mais detalhada foi realizada através das micrografias da secção transversal das sementes sem recobrimento (Figura 2a) e recobertas com CMC/AS 50/50 na concentração de $2 \%$ e com três ciclos de recobrimento (Figuras $2 \mathrm{~b}$ e $2 \mathrm{c}$ ).

Conforme observado na Figura 2, as sementes de feijão apresentam uma camada externa mais densa e resistente com aproximadamente $45 \mu \mathrm{m}$ e uma parte interna de maior porosidade. O filme de recobrimento formado na superfície das sementes utilizando CMC/AS $50 / 50$ na concentração de $2 \%(\mathrm{~m} / \mathrm{v})$ mostra uma característica mais densa do que a camada externa das sementes analisadas e apresenta boa homogeneidade em termos de espessura $(7 \mu \mathrm{m})$.

A homogeneidade no recobrimento, a espessura e a característica densa do filme formado sugerem que o mesmo pode ser utilizado em diferentes sistemas e em diferentes processos de recobrimento.

\section{Absorção e permeação ao vapor de água}

No processo de recobrimento de sementes é importante conhecer a capacidade de absorção e permeação de vapores de água dos filmes formados, com vistas a garantir a hidratação das sementes. As curvas de absorção de água para filmes de CMC, AS e mistura CMC/AS (50/50) nas umidades relativas de 75 e $98 \%$ são mostradas na Figura 3, enquanto que os valores de permeação de vapor de água determinados para os filmes nas composições CMC/AS 100/0, 50/50 e 0/100 e umidades relativas 43, 75 e $98 \%$ são mostrados na Tabela 1 .

Tabela 1. Permeabilidade ao vapor de água dos filmes CMC/AS nas composições 100/0, 50/50 e 0/100 em diferentes umidades relativas

\begin{tabular}{lccc}
\hline $\begin{array}{l}\text { Filmes } \\
\text { CMC/AS }\end{array}$ & $\begin{array}{c}\mathrm{UR} \mathrm{43 \%} \mathrm{WVP} \\
\left(\mathrm{g} \mathrm{m}^{-1} \mathrm{~s}^{-1} \mathrm{~Pa}^{-1}\right)\end{array}$ & $\begin{array}{r}\mathrm{UR} 75 \% \mathrm{WVP} \\
\left(\mathrm{g} \mathrm{m}^{-1} \mathrm{~s}^{-1} \mathrm{~Pa}^{-1}\right)\end{array}$ & $\begin{array}{c}\mathrm{UR} \mathrm{98 \%} \mathrm{WVP} \\
\left(\mathrm{g} \mathrm{m}^{-1} \mathrm{~s}^{-1} \mathrm{~Pa}^{-1}\right)\end{array}$ \\
\hline $100 / 0$ & $5,4 \times 10^{-11}$ & $9,8 \times 10^{-11}$ & $10,0 \times 10^{-11}$ \\
$50 / 50$ & $8,0 \times 10^{-11}$ & $10,3 \times 10^{-11}$ & $10,7 \times 10^{-11}$ \\
$0 / 100$ & $7,6 \times 10^{-11}$ & $7,8 \times 10^{-11}$ & $8,7 \times 10^{-11}$ \\
\hline
\end{tabular}

Em ambas umidades relativas (75 e 98\%, já que não foi observada absorção na UR 43\%), a mesma sequência em termos de absorção de água foi observada, refletindo claramente a maior afinidade do CMC aos vapores de água. Na umidade relativa de $98 \%$ o filme de CMC apresentou uma absorção de cerca de $100 \%$, reduzindo para somente $30 \%$ na UR 75\%. Para o filme de AS as absorções de água
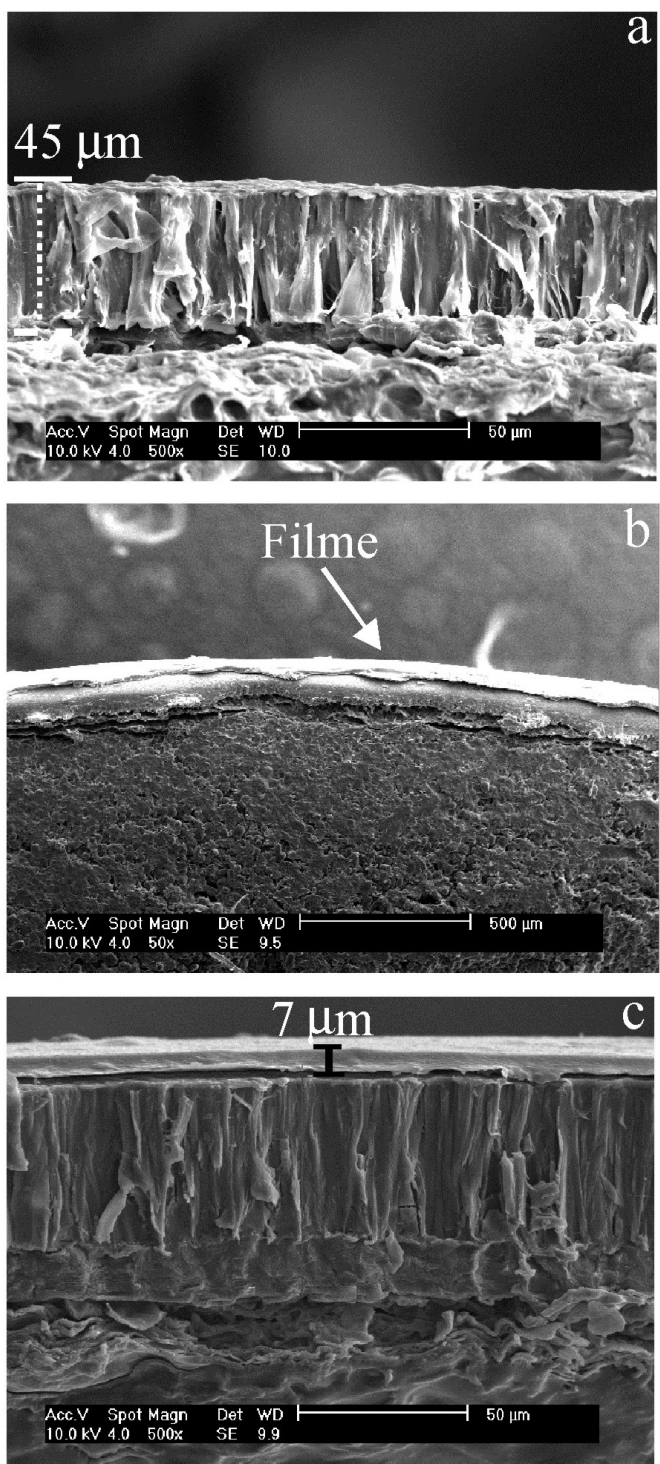

Figura 2. Micrografias das fraturas das sementes analisadas: (a) semente sem recobrimento (ampliação de 500 vezes); (b) recobertas com filme de $\mathrm{CMC/}$ AS 50/50 na concentração de $2 \%(\mathrm{~m} / \mathrm{v})$ e com três ciclos de recobrimento (ampliação de 50 vezes); (c) mesmo que em (b) (ampliação de 500 vezes)

nas umidades de 98 e $75 \%$ foram 65 e $22 \%$, respectivamente, correspondendo a aproximadamente $50 \%$ da absorção determinada para o filme de CMC. A mistura CMC/AS 50/50 mostrou um comportamento intermediário aos biopolímeros puros, ou seja, a absorção alcançou aproximadamente $90 \%$ na UR $98 \%$ e $25 \%$ na UR $75 \%$.

Filmes de alginato de sódio puro foram analisados quanto à absorção de água na UR $43 \%$ por Lima e colaboradores. ${ }^{30}$ Os autores determinaram uma absorção de $16 \%$ nesta condição de umidade. Por outro lado, estudos realizados por Roy e colaboradores ${ }^{31}$ em filmes de glúten de trigo mostraram valores de absorção de água de 25 e $38 \%$ em umidades relativas de 75 e $84 \%$, respectivamente.

Os resultados de permeação mostrados na Tabela 1 foram analisados estatisticamente pela regressão de quadrados médios (teste Tukey $\mathrm{p}<0,05)$. De acordo com a análise é possível comprovar diferenças estatísticas entre a permeabilidade de cada filme polimérico e em relação às diferentes umidades relativas. Analisando separadamente cada umidade, observa-se que na UR $43 \%$, a permeabilidade do filme de CMC difere estatisticamente dos filmes CMC/AS 50/50 e AS (que apresentam valores praticamente iguais). Na UR $75 \%$ a diferença na 
permeabilidade dos filmes de CMC e CMC/AS 50/50 não é significativa, porém, estes diferem estatisticamente da permeabilidade do filme de AS. Na UR 98\%, os valores de permeabilidade são estatisticamente diferentes para os três filmes, sendo que a mistura CMC/AS 50/50 apresenta a maior permeação ao vapor de água.

Na comparação dos filmes individuais com as diferentes umidades relativas estudadas, tem-se que os valores de permeabilidade encontrados para os polímeros CMC e CMC/AS 50/50 diferem estatisticamente. Para o filme de AS os resultados encontrados nas umidades de 43 e $75 \%$ não foram significativamente diferentes, porém estes valores são estatisticamente diferentes dos valores obtidos na UR 98\%.

Os valores acima foram similares aos determinados por Cheng e colaboradores ${ }^{31,32}$ no estudo de WVP e absorção de vapores de água de filmes obtidos a partir de CMC/konjac glucomanana/ácido palminoleico ou $\mathrm{KOH}$ em umidade relativa de $22 \%$. Os valores de WVP encontrados para os filmes contendo CMC variaram de 1,19$1,92 \times 10^{-11} \mathrm{~g} \mathrm{~Pa}^{-1} \mathrm{~s}^{-1} \mathrm{~m}^{-1}$. Por outro lado, os valores de absorção de vapores de água determinados para filmes contendo CMC na UR $75 \%$ foram em torno de $19 \%$. Turhan e colaboradores ${ }^{33}$ avaliaram o efeito de diferentes concentrações de filmes de metilcelulose (MC) nas propriedades de permeação de vapor de água na UR 52\%. O valor encontrado para o filme com concentração de $1,5 \%$ de MC foi de $5,98 \times 10^{-11} \mathrm{~g} \mathrm{~Pa}^{-1} \mathrm{~s}^{-1} \mathrm{~m}^{-1}$, ou seja, similar aos valores determinados no presente estudo. Valores similares de WVP foram também observados por Park e colaboradores ${ }^{34}$ em biofilmes de zeína de milho, metilcelulose e hidroxipropilcelulose em UR $84 \%$.
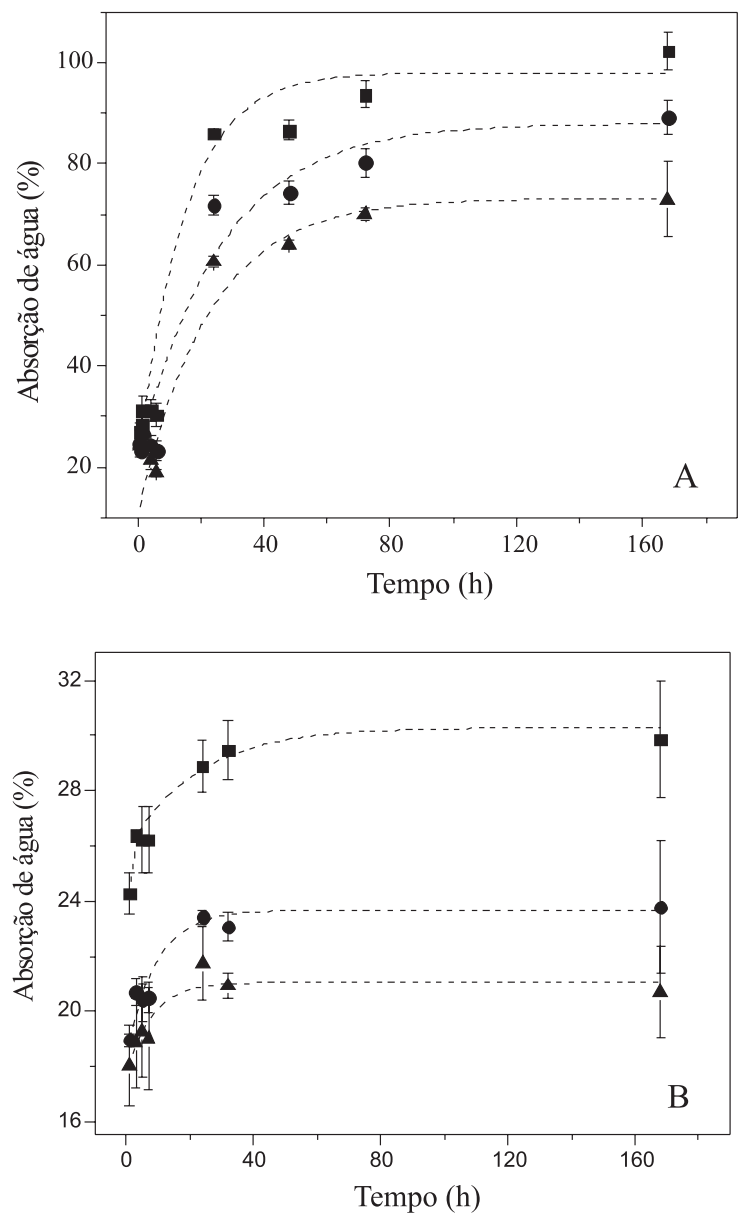

Figura 3. Absorção de vapor de água nas umidades relativas de $98 \%$ (Gráfico A) e 75\% (Gráfico B) dos filmes (2\% m/v) de CMC/AS: (口) 100/0; (• $50 / 50$ e (A) $0 / 100$

\section{Germinação das sementes}

O revestimento das sementes com ambos filmes poliméricos não afetou significativamente o índice de germinação em comparação com as sementes que não foram recobertas (controle) tanto no teste padrão de germinação em casa de vegetação (areia) (Figura 4a) como em laboratório (Figura 4b). Os percentuais de germinação foram em torno de $98 \%$ para estudo nas condições de laboratório e de $88 \%$ em casa de vegetação (areia). A diferença no percentual de germinação entre condições de laboratório e casa de vegetação deve estar associada às diferenças na absorção de água pelos filmes. Quando as sementes são submetidas a uma maior umidade no processo de germinação, ocorre uma maior hidratação das mesmas. Especificamente, no presente estudo, a absorção de água na UR $98 \%$ foi cerca de três vezes maior que na UR 75\% nas sementes recobertas com filmes poliméricos. Por outro lado, a maior capacidade de absorção de água pelos filmes observada na condição de UR $98 \%$ foi, possivelmente, o fator responsável pela ausência de diferenças significativas no percentual de germinação entre os filmes, visto que nas condições de germinação a semente permanece em contato com papel ou areia úmidos o suficiente para não ocorrer falta de água.
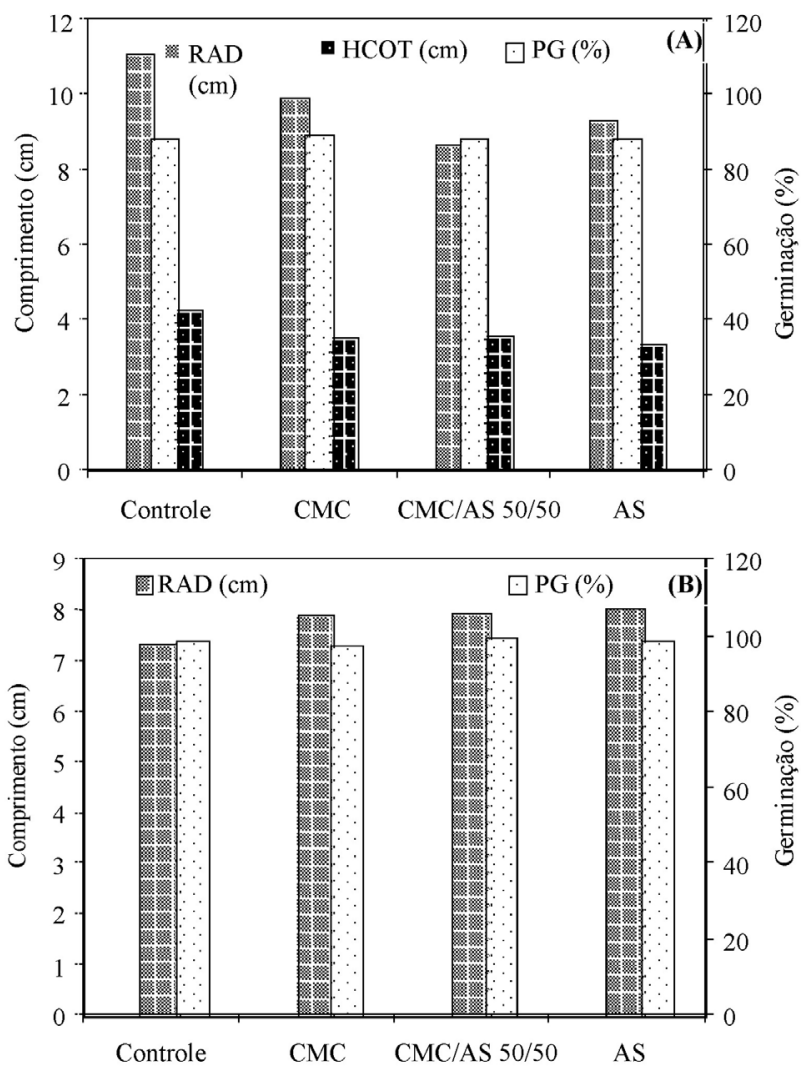

Figura 4. Avaliação do processo de germinação das sementes com recobrimento (solução $2 \% \mathrm{~m} / \mathrm{v}$ ) e sem recobrimento em condições de: (a) casa de vegetação e (b) laboratório. Parâmetros avaliados: comprimento do hipocótilo $(H C O T, \mathrm{~cm})$, da radícula $(R A D, \mathrm{~cm})$ e percentual de germinação $(P G, \%)$

O menor percentual de germinação observado em casa de vegetação pode também ser explicado pela existência de uma barreira física neste processo formada pela areia. Por outro lado, o percentual de germinação é também um indicativo da qualidade fisiológica da semente. Se o processo de germinação for conduzido em areia sob condições controladas de temperatura e umidade, será possível também obter uma resposta do vigor da plântula, desde que sejam consideradas, além do percentual 
de germinação, as medidas de comprimento de radícula e hipocótilo (Figura 4a). Os comprimentos do hipocótilo e radícula diminuíram nas sementes com recobrimento polimérico relativamente à amostra controle, sugerindo um menor desenvolvimento da plântula (menor vigor) (Figura 4a). Na condição de laboratório, o comprimento da radícula foi estatisticamente igual ao valor determinado para a amostra controle, sugerindo que o desenvolvimento da plântula não foi afetado pelo recobrimento polimérico (Figura $4 \mathrm{~b}$ ).

Diferentes concentrações e ciclos de recobrimento analisados para o filme de CMC/AS 50/50, não afetaram significativamente o percentual de germinação. No entanto, na concentração polimérica de $3 \%$, o percentual de germinação das sementes com recobrimento foi $95 \%$, ou seja, menor que o valor de $98,5 \%$ observado para a amostra controle. Por outro lado, para os mesmos filmes com concentrações 1 e $2 \%$ foram determinados valores de 97,7 e $97,8 \%$, respectivamente, que estatisticamente são iguais ao da amostra controle $(98,5 \%)$.

Conforme descrito na literatura, ${ }^{6-12}$ a utilização de filmes no recobrimento de sementes, em geral, não altera o processo de germinação das mesmas. Por outro lado, numa condição de estresse hídrico (falta de água), a presença de filmes de recobrimento poderá absorver água e hidratar a semente favorecendo, assim, a germinação. Ainda, a incorporação de agentes ativos, como nutrientes ou fungicidas, no recobrimento polimérico pode além de oferecer proteção, proporcionar melhores condições para o crescimento da plântula, com melhores respostas em termos de vigor

\section{CONCLUSÕES}

Filmes de carboximetilcelulose, alginato de sódio e suas misturas foram avaliados quanto à presença de interações específicas entre os polímeros, morfologia, absorção de água e viabilidade para utilização em processos de recobrimento de sementes. Análises de infravermelho indicaram a inexistência de ligações químicas fortes entre os componentes da mistura, sugerindo a presença de interações do tipo hidrofóbicas neste sistema. As análises por microscopia eletrônica de varredura comprovaram a formação de filme polimérico denso e homogêneo na superfície das sementes com espessura aproximada de $7 \mu \mathrm{m}$. A formação de filmes com esta característica na superfície das sementes testadas não afetou a capacidade de germinação das mesmas. Em resumo, as características e propriedades dos filmes formados, bem como a capacidade de absorção de água, sugerem viabilidade na utilização desses sistemas em processos de recobrimento de sementes.

\section{MATERIAL SUPLEMENTAR}

No material suplementar disponível em http://quimicanova.sbq. org.br, na forma de arquivo PDF, com acesso livre e gratuito, encontrase a Figura 1S - Micrografias das superfícies das sementes: (a) sem recobrimento e recobertas com soluções poliméricas $(2 \% \mathrm{~m} / \mathrm{v}) \mathrm{CMC} /$ AS: (b) $100 / 0$, (c) 50/50 e (d) 0/100.

\section{AGRADECIMENTOS}

À Universidade Federal de Santa Catarina (UFSC), à Universidade para o Desenvolvimento do Estado de Santa Catarina (UDESC) e ao Conselho Nacional de Desenvolvimento Científico e Tecnológico (CNPq), pelo suporte financeiro.

\section{REFERÊNCIAS}

1. Mente, J. O. M.; Resumos da Semana de atualização em patologia de sementes, Piracicaba, Brasil, 1991.

2. Baudet, L.; Peres, W.; Rev. Seed News 2004, ano VIII, n. 1.

3. Tanada-Palmu, P. S.; Grosso, C. R. F.; Res. Adv. Agric. Food Chem. 2002, 3, 53.

4. Amarante, C.; Banks, N. H.; Horticultural Reviews 2001, 26, 161.

5. Arsego, O.; Baudet, L.; Amaral, A. S.; Hölbig, L.; Peske, F.; Rev. Bras. Sementes 2006, 28, 201.

6. Bays, R.; Baudet, L.; Henning, A. A.; Filho, O. L.; Rev. Bras. Sementes 2007, 29, 60 .

7. Barros, R.G.; Barrigossi, J. A. F.; Costa, J. L. S.; Bragantia 2005, 64, 459.

8. Pereira, C. E.; Oliveira, J. A.; Evangelista, J. R. E.; Ciênc. Agrotec. 2005, 29, 1201.

9. Pires, L. L.; Bragantini, C.; Costa, J. L. S.; Pesq. Agropec. Bras. 2004, 39, 709 .

10. Almeida, C.; Rocha, S. C. S.; Razer, L. F.; Sci. Agric. 2005, 62, 221.

11. Tanada-Palmu, P. S.; Proença, P. S. P.; Trani, P. E.; Passos, F. A.; Grosso, C. R. F.; Bragantia 2005, 4, 291.

12. Batista, J. A.; Tanada-Palmu, P. S.; Passos, F. A.; Trani, P. E.; Grosso, C. R. F.; Hortic. Bras. 2005, 23, 841.

13. Russo, R.; Malinconico, M.; Petti, L.; Romano, G.; J. Polym. Sci., Part B: Polym. Phys. 2005, 43, 1205.

14. Çaykara, T.; Demirci, S.; Eroglu, M. S.; Güven, O.; Polymer 2005, 46, 10750.

15. Nie, H.; Liu, M.; Zhan, F.; Guo, M.; Carbohydr. Polym. 2004, 58, 185.

16. Pourjavardi, A.; Barzegar, S. H.; Mahdavinia, G. R.; Carbohydr. Polym. 2006, 66, 386.

17. Xiao, C.; Lu, Y.; Liu, H.; Zhang, L.; J. Appl. Polym. Sci. 2001, 80, 26.

18. Rhim, J.; LWT--Food Sci. Technol. 2004, 37, 323.

19. Al-Musa, S.; Abu Fara, D.; Badwan, A. A.; J. Controlled Release 1999, $57,223$.

20. Dong, Z.; Wang, Q.; Du, Y.; J. Membr. Sci. 2006, 280, 37.

21. Moldão-Martins, M.; Beirão-da-Costa, S. M.; Beirão-da-Costa, M. L.; Eur. Food Res. Technol. 2003, 217, 325.

22. Isiklan, N.; J. Appl. Polym. Sci. 2006, 99, 1310.

23. Bajpai, A. K.; Giri, A.; Carbohydr. Polym. 2003, 53, 271.

24. Kulkarni, A. R.; Soppimath, K. S.; Aminabhavia, T. M.; Dave, A. M.; Mehta, M. H.; J. Controlled Release. 2000, 63, 97.

25. Fernandez-Perez, M.; Villafranca-Sanchez, M.; Gonzalez-Pradas, E.; Martinez-Lopez, F.; Flores-Cespedes, F. ; J. Agric. Food Chem. 2000, 48, 938.

26. ASTM; Standard test methods for water vapor transmission of materials ASTM E 96-00, Annual Book of ASTM Standards. 2000, 04.06, 842.

27. Brasil, Ministério da Agricultura e Reforma Agrária, Secretaria Nacional de Defesa Agropecuária; Regras para análise de sementes, Brasília, 1992, p. 141-144.

28. Alvarez-Lorenso, C.; Duro, R.; Gómez-Amoza, J. L.; Martinez-Pacheco, R.; Souto, C.; Concheiro, A.; Colloid Polym. Sci. 2001, 279, 1045.

29. Zhang, L. M.; Colloid Polym. Sci. 1999, 227, 886.

30. Lima, A. M. F.; Andreani, L.; Soldi, V.; Borsali, R.; Quim. Nova 2007, 30,832 .

31. Cheng, L. H.; Karim, A. A.; Seow, C. C.; Food Chem. 2008, 107, 411.

32. Cheng, L. H.; Karim, A. A.; Norziah, M. H.; Seow, C. C.; Food Res. Inter. 2002, 35, 829 .

33. Turhan, K. N.; Sahbaz, F.; J. Food Engineering 2004, 61, 459.

34. Park, H. J.; Chinnan, M. S.; J. Food Engineering 1994, 25, 497. 


\section{PREPARAÇÃO, CARACTERIZAÇÃO E PROPRIEDADES DE FILMES POLIMÉRICOS COM POTENCIAL APLICAÇÃO NO RECOBRIMENTO DE SEMENTES}

Aline F. de Oliveira e Valdir Soldi*

Departamento de Química, Universidade Federal de Santa Catarina, 88040-900 Florianópolis - SC, Brasil

Cileide Maria Medeiros Coelho, Aquidauana Miqueloto e Jefferson L. M. Coimbra

Departamento de Fitotecnia, Universidade do Estado de Santa Catarina, 88520-000 Lages - SC, Brasil
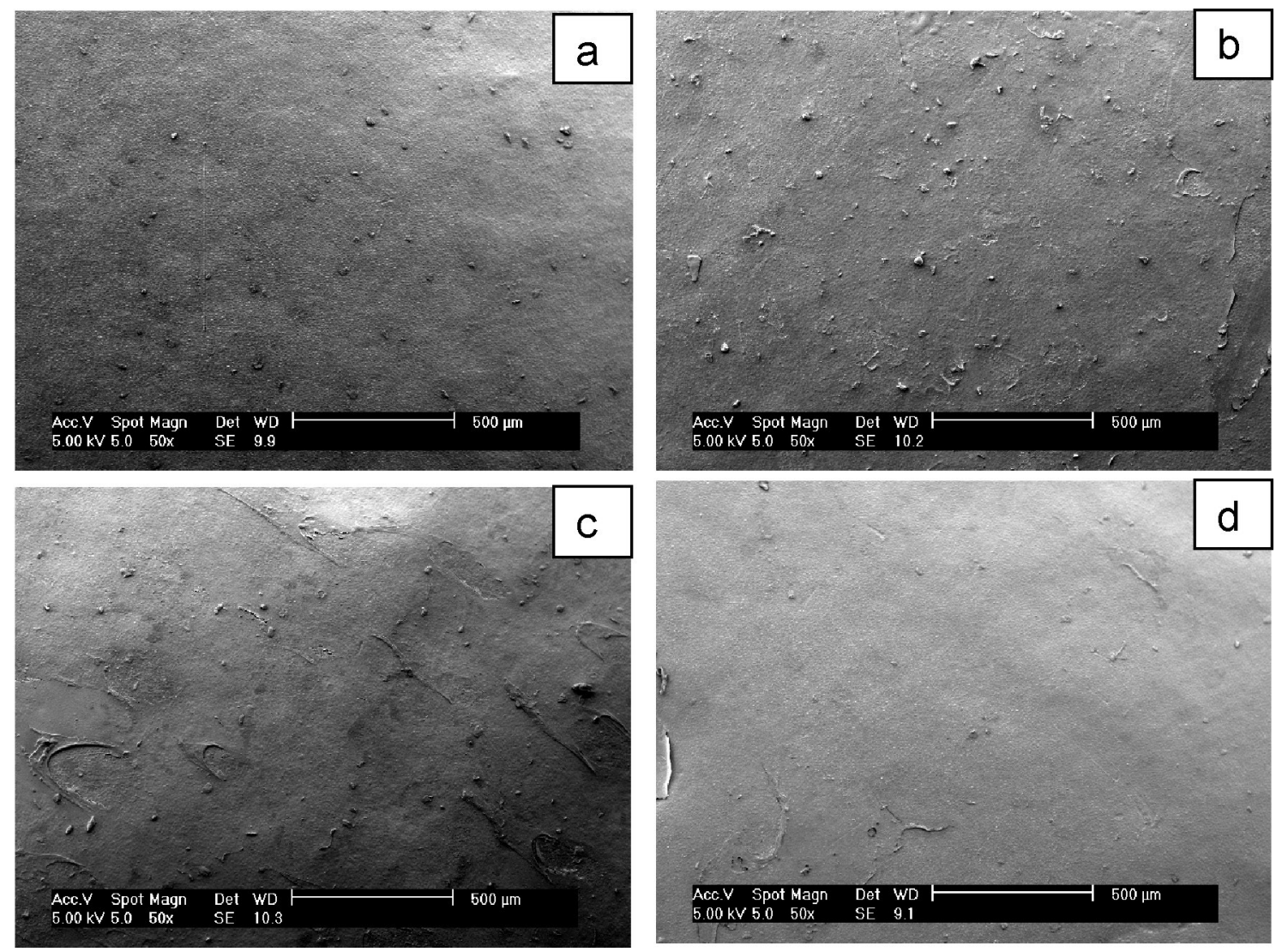

Figura 1S. Micrografias das superfícies das sementes: (a) sem recobrimento e recobertas com soluções poliméricas CMC/AS: (b) 100/0, (c) 50/50 e (d) 0/100 